\title{
Evaluation of Tpeak-Tend and QT Intervals in Chagas' Disease, Chronic Phase and Normal Electrocardiogram
}

\section{Avaliação do Intervalo Tpico-Tfim e QT em Doença de Chagas, Fase Crônica e Eletrocardiograma Normal}

\author{
Abilio Augusto Fragata Filho ${ }^{1}$, Claudia da Silva Fragata1, ${ }^{1}$, Angela Maria Lourenço ${ }^{1}$, \\ Cristiane Castro Faccini ${ }^{1}$, João Ítalo Dias França ${ }^{1}$
}

ORCID IDS

Fragata Filho AA (D) https://orcid.org/0000-0002-9322-3662

Fragata CS (iD https://orcid.org/0000-0002-4056-3380

Lourenço AM (D) https://orcid.org/0000-0002-8609-0347

\author{
Faccini CC (D) https://orcid.org/0000-0002-4056-3380 \\ França JID (D) https://orcid.org/0000-0001-5606-5960
}

\begin{abstract}
Introduction: Chagas' disease lacks elements to predict which carriers will evolve into cardiac form and which will remain in undetermined form. Objective: To evaluate the relationship between electrocardiographic evolution and Tpeak-Tend and QT intervals, both corrected for heart rate, in chagasic patients with normal initial electrocardiogram. Method: Chagasic patients admitted to the institution until 2002 were retrospectively evaluated, and the electrocardiogram was normal at the first consultation. The Tpeak-Tend and QT intervals were measured in milliseconds at the V2 and V5 derivations, with the mean values corrected for heart rate (Bazett). The relationship of these values with the electrocardiographic evolution of the individuals was analyzed, considering the gender, time of evolution and whether they received benznidazole or not. Results: The corrected Tpeak-Tend interval showed no statistical significance among those who maintained or not normal electrocardiogram. The corrected QT interval, the treatment with benznidazole and the time of evolution showed significance for the maintenance of normal electrocardiogram. In the multivariate evaluation, treatment with benznidazole, the QTC interval and the time of evolution were independent variables for the maintenance of normal electrocardiogram. Conclusion: The Tpeak-Tend interval showed no predictor of electrocardiographic evolution. The increased QT interval favored changes.
\end{abstract}

KEYWORDS: Chagas' disease; Tpeak-Tend interval; QT interval.

\section{RESUMO}

Introdução: A doença de Chagas carece de elementos que proporcionem prever quais portadores evoluirão para a forma cardíaca e quais permanecerão na forma indeterminada. Objetivo: Avaliar relação entre evolução eletrocardiográfica e intervalos Tpico-Tfim e QT, ambos corrigidos para a frequência cardíaca, em chagásicos com eletrocardiograma inicial normal. Método: Avaliamos retrospectivamente chagásicos admitidos na instituição até 2002, tendo eletrocardiograma normal na primeira consulta. Os intervalos Tpico-Tfim e QT foram medidos em milissegundos nas derivações V2 e V5, sendo a média dos valores corrigida para a frequência cardíaca (Bazett). Analisou-se a relação desses valores com a evolução eletrocardiográfica dos indivíduos, tendo em vista sexo, tempo de evolução e se receberam benzonidazol ou não. Resultados: O intervalo Tpico-Tfim corrigido não mostrou significância estatística entre os que mantiveram ou não eletrocardiograma normal. O intervalo QT corrigido, o tratamento com benzonidazol e o tempo de evolução mostraram significância quanto à manutenção do eletrocardiograma normal. $\mathrm{Na}$ avaliação multivariada, o tratamento com benzonidazol, o intervalo QTc e o tempo de evolução se mostraram variáveis independentes para a manutenção do eletrocardiograma normal. Conclusão: O intervalo Tpico-Tfim não se mostrou preditor da evolução eletrocardiográfica. O intervalo QT aumentado favoreceu aparecimento de alterações.

PALAVRAS-CHAVE: Doença de Chagas; Intervalo TpicoTfim; Intervalo QT.

1.Instituto Dante Pazzanese de Cardiologia - Laboratório de Doença de Chagas - São Paulo (SP), Brazil

Received: Jan. 16, 2020 | Accepted: Jan. 30, 2019

*Correspondence author: claudiadasilvafragata@gmail.com

Section Editor: José Tarciso Medeiros de Vasconcelos

This research was approved by the Research Ethics Committee of the Instituto Dante Pazzanese de Cardiologia of São Paulo under number 006624/2017. 


\section{INTRODUCTION}

The disease described by Carlos Chagas in 1909 is still a serious public health problem, not only in Latin America but also in several nonendemic countries. Carriers of the parasite, known or not, have migrated to the various continents, transmitting this disease through blood transfusion or organ donation, making this disease currently found in several other continents ${ }^{1}$.

After the acute phase, the chronic phase begins and, initially, there are no clinical manifestations, but only positive serology (indeterminate form: period of the chronic phase that can extend throughout the patient's life, characterized by positive serology - two different techniques - absence of symptoms, surface electrocardiogram, chest X-ray, esophagogram and enema normal opaque). In the late chronic phase, about $40 \%$ of the affected people develop heart disease, which manifests as arrhythmias, heart failure, thromboembolic phenomena and/or sudden death, which can occur regardless of the presence of symptoms, constituting a cause for great concern. There is no known marker that permits to know which patients will develop heart disease and which will remain in indeterminate form throughout their lives ${ }^{1}$.

The analysis of ventricular repolarization, mainly the QT interval and the interval between the $\mathrm{T}$ wave peak and its end (Tpeak-Tend), has interested researchers, considering the evidence of its importance in the risk stratification for the development of severe arrhythmias and sudden death ${ }^{2-6}$.

In patients with left ventricular systolic dysfunction, both ischemic and nonischemic, it was demonstrated that the prolongation of the Tpeak-Tend interval was an independent predictor of ventricular tachyarrhythmias and general mortality ${ }^{3}$. In the presence of pulmonary embolism, it was also found that Tpeak-Tend extended was an early marker of poor evolution ${ }^{4}$. When the corrected QT interval (QTc) was normal, the presence of enlargement of Tpeak-Tend was an independent marker associated with sudden death ${ }^{5}$.

In Chagas' disease, the studies related to the parameters of ventricular repolarization are few and refer to the presence of installed chronic chagasic heart disease and not to patients with normal electrocardiogram. In chagasic patients, with right branch blockade, associated or not with the anterosuperior left bundle of His bundle, the Tpeak-Tend and QT duration were related to increased mortality or the need for heart transplantation ${ }^{6,7}$. Also in patients with chagasic heart disease, the electrophysiological study inducing ventricular arrhythmias by programmed ventricular pacing showed a modest relation (not significant) with the enlargement of Tpeak-Tend ${ }^{8}$.

Considering the scarcity of data available in the literature, analysis of parameters of ventricular electrical activity in patients with Chagas' disease, chronic phase and normal electrocardiogram, is necessary, searching for possible elements that allow the clinical evolution of these patients to be related.

\section{OBJECTIVES}

The objective of this article is to retrospectively evaluate the relationship between the electrocardiographic evolution and the mean values of Tpeak-Tend and QT intervals (corrected by heart rate) measured in normal conventional electrocardiogram in patients with Chagas' disease, chronic phase, treated or not with benznidazole.

\section{METHODOLOGY}

The charts of patients with Chagas' disease confirmed by two or more serum reaction techniques were analyzed from the database of the Chagas' Disease Laboratory of the Dante Pazzanese Institute of Cardiology.

Inclusion criteria were: 1) to be in chronic phase, admitted to the institution in 2002 or before; 2) normal conventional electrocardiogram in the first consultation (speed of $25 \mathrm{~mm} / \mathrm{s}$ and amplitude of $1 \mathrm{mv} / \mathrm{mm}$ ); 3) treated or not with benznidazole; 4) both genders; 5) no age restriction. There were no exclusion criteria.

In no patient esophagogram or opaque enema were performed, which is why they are not referred to in this article with indeterminate form, but as chagasic patients and normal electrocardiogram.

The V2 and V5 derivations of the conventional electrocardiogram were used, digitalized and amplified for perfect visualization and manual time measurement: Tpeak-Tend and QT, and the mean of these values was then obtained (Fig. 1). The following measures were also obtained: (i) heart rate (HR) measured in beats per minute (bpm); (ii) Tpeak-Tend interval corrected 


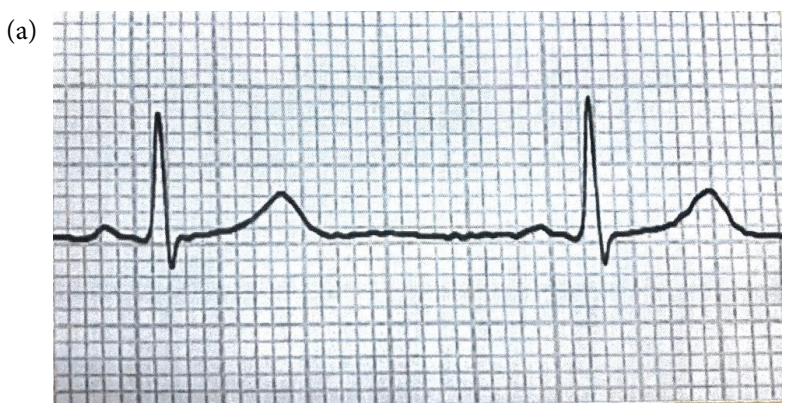

(b)

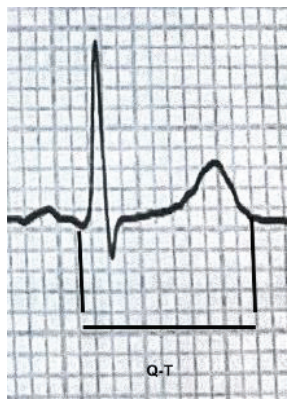

(c)

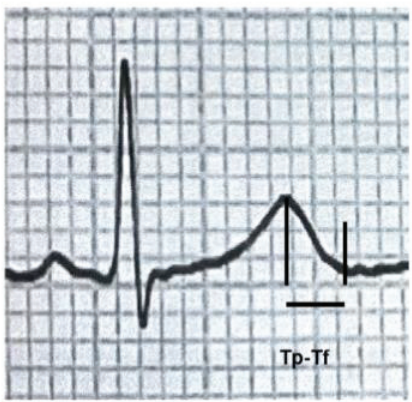

Figure 1. Conventional enlarged electrocardiogram.

( $\mathrm{Tp}-\mathrm{Tf}$ )c for HR in milliseconds (ms); (iii) corrected QT interval for heart rate (QTc) in ms.

The occurrence of heart disease (characterized by the appearance of electrocardiographic changes in the last tracing of the patient) was analyzed, with a minimum follow-up period of 10 years.

The arithmetic means of $\mathrm{QT} c$ and $(\mathrm{Tp}-\mathrm{Tf}) \mathrm{c}$ values were related to: age (mean-standard deviation) in years; gender (male-female); treatment with benznidazole (yes-no); time of evolution in years; evolution to heart disease (yes-no). The different ethnicities were not analyzed because there was no objective verification, but rather data collected from the medical records.

The FC was obtained by dividing $60,000 \mathrm{~ms}$ by the $\mathrm{R}-\mathrm{R}$ interval in milliseconds $(60,000 \mathrm{~ms} / \mathrm{R}-\mathrm{R} \mathrm{ms})$. When the $\mathrm{R}-\mathrm{R}$ intervals were not regular, the mean of 3 beats was obtained. The QT interval was measured in $\mathrm{ms}$ from the beginning of the QRS complex to the end of the $\mathrm{T}$ wave (representing the total duration of ventricular electrical activity). The QTc interval was obtained by the Bazett's formula, which consists of the division of the QT interval, measured in $\mathrm{ms}$, by the square root of the R-R interval also in $\mathrm{ms}$ ( $\mathrm{QTc}=\mathrm{QT} / \sqrt{\mathrm{R}-\mathrm{R}}$ ), thus providing the value of the QT interval adjusted for heart rate. For heart rates below $60 \mathrm{bpm}$ or above $90 \mathrm{bpm}$, linear formulas were used, such as those of Framingham:

$$
\text { QT linear correction - QTcl: QT + } 0.154(1-\mathrm{R}-\mathrm{R})
$$

and Hodges ${ }^{10,11}$ (Fig. 1b):

QT linear correction - QTm: QT + $1.75(\mathrm{HR}-60)$

The Tpeak-Tend interval was measured in $\mathrm{ms}$, between the peak of the $\mathrm{T}$ wave and its end, correcting for the heart rate, using the Bazett's formula, with substitution of QT for Tpeak-Tend (Fig. 1c).

The statistical analysis was performed evaluating the relation of the means of the values of $\mathrm{QTc}$ and $(\mathrm{Tp}-\mathrm{Tf}) \mathrm{c}$ with the described parameters, using the IBM SPSS software version 19 (ARMONK NY).

\section{RESULTS}

A total of 291 patients who met the inclusion criteria were analyzed. Of those, 59 with $\mathrm{HR}<60$ and $9>90 \mathrm{bpm}$. Using the Bazett's formula for the QTc calculation, the mean was $408.35 \mathrm{~ms}$ and, applying the Hodges's formula in $\mathrm{CF}$ patients < 60 or $>90 \mathrm{bpm}$, the QTc mean was $406.85 \mathrm{~ms}$, without significant difference. Table 1 shows the univariate analysis of the characteristics studied.

In this univariate analysis, it was observed that the heart rate, $\mathrm{Tp}-\mathrm{Tf}$ and $(\mathrm{Tp}-\mathrm{Tf}) \mathrm{c}$ intervals, age and gender had no statistically significant difference between patients who remained with normal electrocardiogram and those whose electrocardiogram changed. The QT, QTc intervals and the time of evolution were greater in patients who had their electrocardiogram altered, while patients treated with benznidazole remained in greater numbers with normal electrocardiogram, these three with statistically significant differences. Table 2 shows the multivariate analysis of the occurrence of electrocardiogram alterations.

In the multivariate analysis, considering the change in the electrocardiogram, the patients treated with benznidazole had a lower percentage of changes in the electrocardiographic tracing. These results have been previously demonstrated ${ }^{12}$; patients with longer evolution time presented more altered tests. The progressively greater QTc favored the appearance of alterations of 
Table 1. Univariate heart rate analysis, $Q T c,(T p-T f) c$, age, gender, treatment with benznidazole, time of evolution of patients who maintained normal ECG or not, with a minimum follow-up of 10 years.

\begin{tabular}{|c|c|c|c|c|c|c|c|}
\hline \multirow{3}{*}{ Variable } & \multirow{2}{*}{\multicolumn{2}{|c|}{ General }} & \multicolumn{4}{|c|}{ Normal ECG } & \multirow{3}{*}{ P-value } \\
\hline & & & \multicolumn{2}{|c|}{ No } & \multicolumn{2}{|c|}{ Yes } & \\
\hline & $\begin{array}{c}\text { Number or } \\
\text { mean }\end{array}$ & $\begin{array}{c}\% \\
\text { or D.P. }\end{array}$ & $\begin{array}{c}\text { Number or } \\
\text { mean }\end{array}$ & $\begin{array}{c}\% \\
\text { or D.P. }\end{array}$ & $\begin{array}{c}\text { Number or } \\
\text { mean }\end{array}$ & $\begin{array}{c}\% \\
\text { or D.P. }\end{array}$ & \\
\hline Hear Rate & 67.2 & 11.1 & 65.5 & 9.6 & 67.8 & 11.5 & 0.1962 \\
\hline QT m & 378.97 & 35.28 & 388.53 & 35.29 & 375.65 & 34.74 & 0.0065 \\
\hline QTc m & 399.1 & 33.6 & 406.9 & 41.1 & 396.4 & 30.2 & 0.0383 \\
\hline (TpTf) $m$ & 84.33 & 11.10 & 85.87 & 12.64 & 83.80 & 10.50 & 0.2624 \\
\hline$(T p T f) c m$ & 89.2 & 13.2 & 90.0 & 14.9 & 88.9 & 12.5 & 0.7886 \\
\hline T. evolution & 19.6 & 6.4 & 22.3 & 6.5 & 18.7 & 6.1 & 0.0000 \\
\hline Age & 38.2 & 10.2 & 38.3 & 9.9 & 38.1 & 10.3 & 0.9156 \\
\hline Male gender & 101 & 34.8 & 24 & 32.0 & 77 & 35.8 & 0.5766 \\
\hline Treatment & 248 & 85.2 & 53 & 70.7 & 195 & 90.3 & 0.0001 \\
\hline
\end{tabular}

Table 2. Multivariate analysis between altered ECG and the variables age, gender, treatment with benznidazole, time of evolution, and QTcm.

\begin{tabular}{ccccc}
\hline \multirow{2}{*}{ Variable } & \multirow{2}{*}{ Odds Ratio } & \multicolumn{2}{c}{ 95\% Cl } & \multirow{2}{*}{ P-value } \\
\cline { 3 - 4 } & & Inferior Limit & Superior Limit & 0.9395 \\
\hline Age & 1.001 & 0.967 & 1.037 & 0.7529 \\
\hline Male gender & 1.106 & 0.590 & 2.075 & 0.0018 \\
\hline Benznidazole & 0.262 & 0.113 & 0.607 & 0.0005 \\
\hline T. Evolution & 1.091 & 1.039 & 1.146 & 0.0297 \\
\hline QTcm & 1.010 & 1.001 & 1.019 & \\
\hline
\end{tabular}

the electrocardiogram. These three variables behaved independently.

\section{DISCUSSION}

Chagas' disease in its chronic phase is characterized by indeterminate and clinical forms, the former persisting indefinitely in about $60 \%$ of affected individuals. There are no markers to identify which patients will remain indeterminate forever or those who, after a variable period of time, will evolve to heart disease. The analysis of ventricular repolarization has shown to be an important prognostic value in several heart diseases ${ }^{13}$.

$\mathrm{T} \mathrm{p}-\mathrm{Tf}$ values above $100 \mathrm{~ms}$ are considered abnormal, with little data available for values corrected for $\mathrm{HR}^{4}$. For QTc values, it is known that they vary with gender and are accepted as normal up to a maximum of $450 \mathrm{~ms}$ for men and $470 \mathrm{~ms}$ for women ${ }^{9}$.

Several studies have highlighted the importance of the parameters of electrical activity and ventricular repolarization in several heart diseases with electrocardiographic alterations, but not in diseases (such as Chagas' disease) with normal electrocardiogram ${ }^{3-7}$.

In an evaluation of 272 patients with acute pulmonary embolism, it was observed that Tp-Tf values above $126 \mathrm{~ms}$ were predictors of morbidity and mortality, with sensitivity of $80.56 \%$, specificity of $59.32 \%$, negative predictive value of $95.2 \%$ and positive predictive value of $23.2 \%{ }^{4}$.

Analyzing 50 patients with slow coronary flow and 40 controls, the authors observed a significantly higher increase of ( $\mathrm{Tp}-\mathrm{Tf})$ and QTc in those with changes in the flow velocity in the coronary arteries, compared to controls ${ }^{14}$.

From 327 patients with ejection fraction $\leq 35 \%$, carriers of implantable cardioverter-defibrillator, it was observed that in a period of $17 \pm 12$ months there were appropriate shocks in $59(18 \%)$ and in $30 \pm 13$ months, 67 (21\%) died. The Tp-Tf interval was an independent variable, with each increase of $10 \mathrm{~ms}$, there was an 
increase of 1.16 in appropriate shocks and 1.14 in mortality from any cause ${ }^{3}$.

Assessing 695 patients with coronary disease, 353 with sudden death (recovered or not), the authors observed that the Tp-Tf interval measured in the V5 derivation of the conventional electrocardiogram, proved to be a predictor of this event, especially when the QTc interval was normal ${ }^{5}$.

In 105 patients with chronic chagasic cardiopathy (abnormal ECG) submitted to electrophysiological study and induction or not of sustained ventricular arrhythmia, it was observed that the Tp-Tf interval greater than $100 \mathrm{~ms}$ showed a tendency (p: 0.07) to identify patients with higher risk of ventricular arrhythmias ${ }^{8}$.

Following 738 chronic chagasic heart disease patients for $58 \pm 39$ months, the authors observed that the analysis of the QT interval, but not the Tp-Tf, was an important predictor of mortality in these patients ${ }^{6}$.

In the present study, 291 chronic chagasic patients were retrospectively evaluated, with a normal electrocardiogram at the first consultation and its evolution after about two decades. The prognostic value of the (Tp-Tf)c and QTc intervals was evaluated and measured on the normal electrocardiogram at admission, relating these measures to the maintenance of the normal electrocardiogram or the appearance of any abnormalities in the electrocardiographic trace. In agreement with the data in the literature, the $\mathrm{Tp}-\mathrm{Tf}$ and $(\mathrm{Tp}-\mathrm{Tf}) \mathrm{c}$ intervals did not differ among the patients who remained with normal or altered electrocardiogram, not being a marker of electrocardiographic evolution in chagasic patients with normal electrocardiogram.

In a retrospective study, with two decades of observation, the importance of parasitic treatment with benznidazole in the maintenance of normal electrocardiogram was previously demonstrated ${ }^{12}$. Although it was not part of the objective of this study, the result was maintained in this evaluation, with the parasiticide treatment as an independent variable, favoring the maintenance of the normal electrocardiogram ( $75 \%$ decrease of chances of alterations in the tracing - Table 2).

The QTc and the time of evolution were independent variables, and the greater these parameters, the greater the chances of alterations in the electrocardiogram. According to Table 2, at each unit more than QTc there was an increase in the chance of the electrocardiographic tracing being altered by $0.9 \%$ and, at each year of evolution, these chances were $9.1 \%$.

Based on the Youden criterion ${ }^{15}$, the best cut-off point, maximizing the accuracy, would be QTc of $425.5 \mathrm{~ms}$, which would provide a sensitivity of $37.3 \%$ and specificity of $81.5 \%$. As in this study the QTc analysis was made in patients with normal electrocardiogram, the authors believe that the sensitivity and not the specificity should be prioritized, as values are being sought that may indicate a higher probability of appearance of electrocardiographic abnormalities. Therefore, a cut-off level with a sensitivity of $80 \%$ was chosen, which corresponds to the QTc value of $372 \mathrm{~ms}$, although the specificity would be $21.3 \%$ with this value. It would be more appropriate to identify the greater number of patients with normal electrocardiograms who would have a greater chance of presenting alterations in the electrocardiographic tracing, even with the existence of many false positives that would be screened with other methods.

Thus, the analysis of the Tp-Tf interval in patients with Chagas' disease, chronic phase and normal electrocardiogram, was not able to identify patients who would or would not maintain normal electrocardiographic tracing. On the other hand, the QTc above $372 \mathrm{~ms}$ was shown with $80 \%$ sensitivity and $21.3 \%$ specificity in identifying those with greater chance of presenting electrocardiographic alterations and that, therefore, should be evaluated with more concern.

\section{CONCLUSION}

In the present study, patients with chronic phase of Chagas' disease and normal electrocardiogram, Tp-Tf interval corrected by heart rate, did not show prognostic marker of maintenance of normal electrocardiogram. However, the greater the QTc interval (above $372 \mathrm{~ms}$ ) the greater the chances of the patient to present evolutionary alterations of the electrocardiogram.

This is a retrospective study that analyzed the measurements of $\mathrm{Tp}-\mathrm{Tf}$ and QT manually. The target was only the presence or absence of any changes in the electrocardiogram after two decades of follow-up, starting from a normal tracing, without evaluating other manifestations that may be compatible with heart disease. 


\section{REFERENCES}

1. Vieira, JF, Távora FRF, Sobral GV, Vasconcelos GG, Almeida GPL, Fernandes JR, et al. Chagas cardiomyopathy in Latin America review. Current Cardiology Reports, 2019;21(2):8. https://doi.org/10.1007/s11886-019-1095-y

2. Dias JCP, Ramos Jr. AN, Gontijo ED, Luquetti A, ShikanaiYasuda MA, Coura JR, et al. II Consenso Brasileiro em Doença de Chagas, 2015. Epidemiol Serv Saúde, 2016;25(núm. esp.):7-86. https://doi.org/10.5123/S167949742016000500002

3. Morin DP, Saad MN, Shams OF, Owen JS, Xue JQ, Freddy M, et al. Relationships between the T-peak to T-end interval, ventricular tachyarrhythmia, and death in left ventricular systolic dysfunction. Europace, 2012;14(8):1172-9. https:// doi.org/10.1093/europace/eur426

4. Icli A, Kayrak M, Akilli H, Aribas A, Coskun M, Ozer SF, Ozdemir K. Prognostic value of Tpeak-Tend interval in patients with acute pulmonary embolism. BMC Cardiovascular Disorders, 2015;15(99):1-8. https://doi.org/10.1186/s12872-015-0091-4

5. Panikkath R, Reinier K, Uy-Evanado A, Teodorescu C, Hattenhauer J, Mariani R, et al. Prolonged Tpeak-toTend interval on the resting ECG is associated with increased risk of sudden cardiac death. Circ Arrhythm Electrophysiol, 2011;4(4):441-7. https://doi.org/10.1161/ CIRCEP.110.960658

6. Salles G, Xavier S, Sousa A, Hasslocher-Moreno A, Cardoso C. Prognostic value of QT interval parameters for mortality risk stratification in Chagas': disease results of a long-term follow-up study. Circulation, 2003;108(3):305-12. https:// doi.org/10.1161/01.CIR.0000079174.13444.9C

7. Bradfield J, Woodbury B, Traina M, Hernandez S, Sanchez D, Wachsner R, et al. Repolarization parameters are associated with mortality in Chagas disease patients in the United States. Indian Pacing Electrophysiol J, 2014;14(4):171-80. https:// doi.org/10.1016/s0972-6292(16)30773-2

8. Armaganijan L, Moreira DA, Nolasco de Araújo RR, Puzzi MA, Munhoz FP, Carvalho MJ, et al. The usefulness of T-wave peak to T-wave end interval in identifying malignant arrhythmias in patients with Chagas disease. Hellenic J Cardiol, 2013;54(6):429-34.

9. Pastore CA, Pinho JA, Pinho C, Samesima N, Pereira-Filho HG, Kruse JCL, et al. III Diretrizes da Sociedade Brasileira de Cardiologia sobre análise e emissão de laudos eletrocardiográficos. Arq Bras Cardiol, 2016;106(4 supl.1):123. https://doi.org/10.5935/abc.20160054

10. Sagie A, Larson MG, Goldberg RJ, Bengston JR, Levy D. An improved method for adjusting the QT interval for heart rate (the Framingham Heart Study). Am J Cardiol. 1992;79(7):797801. https://doi.org/10.1016/0002-9149(92)90562-d

11. Hodges M, Salerno D, Erlien D. Bazett's QT correction reviewed: evidence that a linear QT correction for heart is better [abstract]. J Am Coll Cardiol, 1983;1(2):694.

12. Fragata-Filho AA, França FF, Fragata CS, Lourenço AM, Faccini CC, Costa CAJ. Evaluation of parasiticide treatment with benznidazol in the electrocardiographic, clinical, and serological evolution of Chagas disease. PLoS Negl Trop Dis, 2016;10(3):e0004508. https://doi.org/10.1371/journal. pntd.0004508

13. Kors JA, Ritsema van Eck HJ, van Herpen G. The meaning of the Tp-Te interval and its diagnostic value. J Electrocardiol, 2008;41(6):575-80. https://doi.org/10.1016/j. jelectrocard.2008.07.030

14. Tenekecioglu E, Karaagac K, Yontar OC, Agca FV, Ozluk OA, Tutuncu A, et al. Evaluation of Tp-Te Interval and Tp-Te/ QT ratio in patients with coronary slow flow Tp-Te/QT ratio and coronary slow flow. Eurasian J Med, 2015;47(2):104-8. https://doi.org/10.5152/eurasianjmed.2015.72

15. Youden WJ. Index for rating diagnostic tests. Cancer, 1950;3(1):32-5. https://doi.org/10.1002/10970142(1950) 3:1<32::aid-cncr2820030106>3.0.co;2-3 